\title{
Microstructure and Mechanical Properties of Tortoise Carapace Structure Bio-Inspired Hybrid Composite
}

\author{
Bao-Shuai Han ${ }^{1,2} \cdot$ Yan-Jin Xu ${ }^{1} \cdot$ En-Yu Guo ${ }^{3} \cdot$ Tao Jing $^{4} \cdot$ Hong-Liang Hou ${ }^{1}$ Liang-Shun Luo ${ }^{2}$
}

Received: 7 October 2017 / Revised: 4 February 2018/ Published online: 20 April 2018

(C) The Chinese Society for Metals and Springer-Verlag GmbH Germany, part of Springer Nature 2018

\begin{abstract}
A turtle carapace bio-inspired $\mathrm{Ti}$ matrix hybrid composite was successfully fabricated in this work. This composite incorporates two parts: the Ti-Al intermetallic multilayered composite and continuous $\mathrm{SiC}$ fibers-reinforced $\mathrm{Ti}$ matrix composite. In the $\mathrm{Ti}-\mathrm{Al}$ intermetallic multilayered composite part, a series of $\mathrm{Ti}-\mathrm{Al}$ intermetallics compounds, including $\mathrm{Ti}_{3} \mathrm{Al}$, TiAl, $\mathrm{TiAl}_{2}$ and $\mathrm{TiAl}_{3}$, were formed between the Ti layers. In the continuous $\mathrm{SiC}$ fibers-reinforced $\mathrm{Ti}$ matrix composite part, $\mathrm{SiC}$ fibers and Ti matrix were found to be bonded well through weak interface reaction. Flexural strength of this material reached $1.21 \pm 0.16 \mathrm{GPa}$, measured by three-point bending test. The deformation features suggest that the hierarchical structure combining ductile Ti layers/matrix with brittle high-strength $\mathrm{Ti}-\mathrm{Al}$ intermetallics layers/SiC fibers can effectively enhance the mechanical properties of the bio-inspired hybrid composite.
\end{abstract}

Keywords Bio-inspired composite $\cdot$ Hierarchical structure $\cdot$ Cracks propagation $\cdot$ Flexural property

\section{Introduction}

Carapace plays an important role in the physical protection and nutrition transmission for turtle [1]. With the protection of carapace, turtles can bear high water pressure and protect themselves from traumas caused by falling, smashing against rocks and predator assaults [2]. Over the past years, many researchers have been focused on revealing the relationship between the structure and the resulting performance of turtle carapace [3-5].

Available online at http://link.springer.com/journal/40195

Yan-Jin Xu

xuyj_avic@qq.com

$\triangle$ Liang-Shun Luo

luols@hit.edu.cn

1 AVIC Manufacturing Technology Institute, Beijing, Beijing 100024, China

2 School of Materials Science and Engineering, Harbin Institute of Technology, Harbin 150001, China

3 School of Materials Science and Engineering, Dalian University of Technology, Dalian 116024, China

4 School of Materials Science and Engineering, Tsinghua University, Beijing 100084, China
A typical model, taking the carapace of the red-eared slider turtle as a sample, has been confirmed, and the schematic demonstrating the carapace cross-sectional structure is shown in Fig. 1. The basic architecture of the carapace is a sandwich structure, which can be regarded as hierarchical composite [6]. The epidermal layer is keratin laminate, formed of many submicron layers, which is the first barrier to external loads due to its high stiffness. The underneath layer is formed of dorsal cortex, whose osteons are randomly embedded in the disordered woven fiber bundle matrix. The dorsal cortex can withstand sharp impacts such as biting or clawing, and it is also beneficial for preventing cracks propagation. The next layer of turtle carapace is cancellous interior layer, which forms the majority of the carapace structure. This layer is capable of absorbing large amount of energy under external impacting forces. The innermost layer is ventral cortex layer, consisting of two distinct fiber sub-layers, which is conducive to structural support. Due to its unique structure, turtle carapace possesses good compression resistance [2, 4, 7], high bending resistance $[4,8,9]$ and excellent impact resistance $[10,11]$.

The structure of turtle carapace can be regarded as a biological armor. The excellent protection performance has attracted an increasing attention, and many studies have been conducted to fabricate materials with similar 


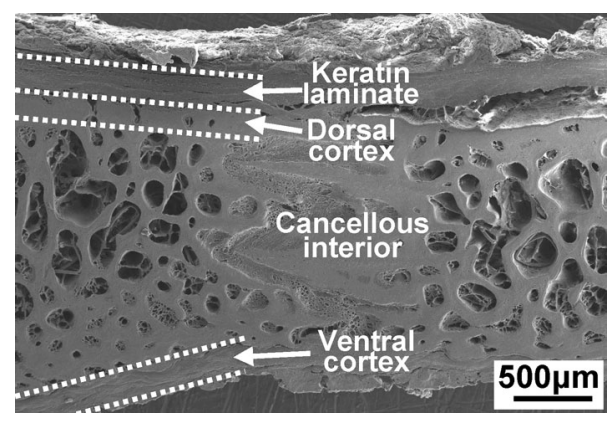

Fig. 1 Cross-sectional structure of turtle carapace

structures. For example, a multilayered structure of Ti-Al intermetallics has been fabricated and studied extensively $[12,13]$. A series of $\mathrm{Ti}-\mathrm{Al}$ intermetallic compounds, including $\mathrm{Ti}_{3} \mathrm{Al}, \mathrm{TiAl}, \mathrm{TiAl}_{3}$ and $\mathrm{TiAl}_{2}$, were incorporated in this material. This special structure combining ductile $\mathrm{Ti}$ layers with brittle $\mathrm{Ti}-\mathrm{Al}$ intermetallic compound layers possesses low density, high strength, and excellent creep and corrosion resistance [14-16]. Cracks propagation can be effectively suppressed by the layered structure [17]. Recently, manufacturing and application of fiber-reinforced materials have also become hot topic in biomimetic materials [18-20]. Because of the strengthening effect of the fibers, the toughness, elastic modulus and strength of the composite material have been greatly improved [21]. Many types of fibers, such as carbon fibers [22, 23], carbon nanotube fibers [24] and SiC fibers [25, 26], have been widely used to reinforce the biomimetic composite materials. Recent studies have reported the successful application of continuous $\mathrm{SiC}$ fibers in Ti matrix, Al matrix and ceramic matrix composites due to its low density, high strength and high modulus [27-29].

In this study, we designed a new tortoise carapace bioinspired hybrid composite by combining the $\mathrm{Ti} / \mathrm{Ti}-\mathrm{Al}$ intermetallic multilayered composite with continuous $\mathrm{SiC}$ fibers-reinforced $\mathrm{Ti}$ matrix composite. For this hybrid composite, the function of $\mathrm{Ti}-\mathrm{Al}$ intermetallic multilayer composite is similar to that of the keratin laminate of tortoise carapace, while the $\mathrm{SiC}$ fibers-reinforced $\mathrm{Ti}$ matrix composite acts in a similar way as the dorsal cortex layer of tortoise carapace. Flexural test was performed to evaluate the mechanical properties of this material. Microstructure and fracture surfaces of the samples were examined by scanning electron microscopy (SEM). In addition, deformation and cracks propagation were also analyzed and discussed in this study.

\section{Materials and Methods}

\subsection{Materials Preparation}

Figure 2a shows the stacking sequence of the hybrid composite. The foil-fiber-foil method was adopted to fabricate the bio-inspired hybrid composite. Pure titanium foils $(100 \mu \mathrm{m}$ thick) and pure aluminum foils $(20 \mu \mathrm{m}$ thick) were cleaned carefully and then cut into square strips with a dimension of $36 \times 36 \mathrm{~mm}^{2}$ for further use. $\mathrm{SiC}$ fibers were used as the reinforcing component. This fiber comprises of a tungsten core $(16 \mu \mathrm{m}$ in diameter) and a surrounding cylindrical $\mathrm{SiC}$ crystal layer ( $38 \mu \mathrm{m}$ thick). In addition, carbon-coated layer of $2 \mu \mathrm{m}$ thickness is deposited on the surface of $\mathrm{SiC}$ crystal layer by the method of chemical vapor deposition (CVD). For the finally fabricated bio-inspired hybrid composite, the Ti-Al intermetallic multilayered composite part has the same thickness as the continuous SiC fibers-reinforced Ti matrix composite part.

The bio-inspired hybrid composite specimen was prepared by the method of vacuum hot-pressing sintering. The preparation process, as shown in Fig. 2b, contains several steps. First, the specimen was heated to $625{ }^{\circ} \mathrm{C}$ under a pressure of $5 \mathrm{MPa}$ in vacuum to minimize the space between the adjacent foils and then was kept at this temperature for $2 \mathrm{~h}$ to initiate the interdiffusion reaction between the $\mathrm{Ti}$ and $\mathrm{Al}$ foils. Second, the temperature was set at $650{ }^{\circ} \mathrm{C}$ for $3 \mathrm{~h}$ to promote the interdiffusion reaction, and then, the pressure was removed. Finally, the temperature was further increased to $900{ }^{\circ} \mathrm{C}$ and kept for $1 \mathrm{~h}$. Ten minutes later after the temperature was stable, the pressure was increased to $30 \mathrm{MPa}$.

\subsection{Materials Characterization}

The specimen of the bio-inspired hybrid composite is initially ground with $\mathrm{SiC}$ papers and then polished by diamond suspensions $(0.5 \mu \mathrm{m}$ particle size $)$. The microstructure and fractured surfaces of the samples were examined by scanning electron microscopy (SEM, Quanta 200FEG, FEI Co., USA) equipped with energy-dispersive $\mathrm{X}$-ray spectrometry (EDXS) system. Phases of the material were characterized by the X-ray diffraction (XRD) technique using a $\mathrm{Cu} K_{\alpha}$ radiation (X'PERT PRO MPD, PANalytical BV, Netherlands).

\subsection{Three-Point Bending Test}

The specimen of the bio-inspired hybrid composite was machined to the dimension of $35 \times 4 \times 3 \mathrm{~mm}^{3}$ (length $\times$ width $\times$ thickness). Three-point bending test 

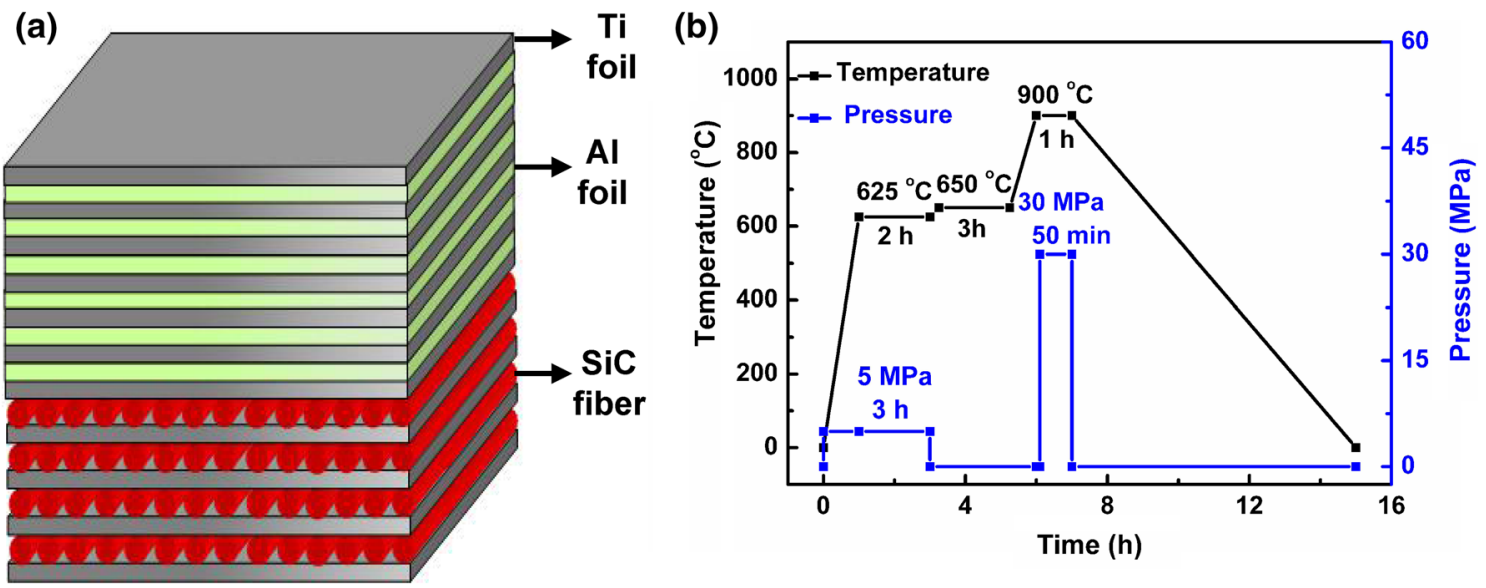

Fig. 2 Schematic of a the components stacking sequence, $\mathbf{b}$ the processing route to fabricate the hybrid composite by hot-pressing sintering

was carried out on a mechanical testing machine (Instron 5569 , Instron Co., USA) with a maximum load of $50 \mathrm{kN}$. In the three-point bending test, the supporting span was $30 \mathrm{~mm}$ and the loading rate was set at $0.5 \mathrm{~mm} / \mathrm{min}$. The flexural strength $\sigma_{\max }$ was calculated by the equation: $\sigma_{\text {max }}=3 F_{\text {max }} \times L /(2 \times b \times h \times h)$, where $F_{\text {max }}$ is the maximum load value, $L$ the supporting span, and $b$ and $h$ the width and thickness of the tested specimen, respectively. To eliminate error, the test was repeated for five times. In one of the series bending tests, load was removed when the load got o decreased after maximum load, and the lateral fracture surface was examined by SEM. The load was directly applied on the top surface of continuous SiC fibers-reinforced Ti matrix composite part.

\section{Results and Discussion}

\subsection{Microstructure Characteristics}

Two parts are successfully incorporated in this hybrid composite material, as shown in Fig. 3a-d. The top part is the Ti-Al intermetallic multilayered composite (Fig. 3b), and the bottom part is the continuous $\mathrm{SiC}$ fibers-reinforced Ti matrix composite (Fig. 3c, d). It was reported that voids can be easily formed between the $\mathrm{Ti}-\mathrm{Al}$ layers during the fabrication process [30]; however, these Ti-Al layers are well bonded without any gaps (Fig. 3b) in this work. In the other part, SiC fibers were also well bonded with the $\mathrm{Ti}$ matrix (Fig. 3c, d). No obvious defect, such as crack, gap and impurity, was detected. In our study, the interface binding ratio [31] was measured to be $99 \%$, indicating an excellent quality.

Multi-sub-layers structure with a zigzag shape was found in the $\mathrm{Ti}-\mathrm{Al}$ intermetallic multilayered part (Fig. 3b), suggesting the formation of different phases. The XRD result (Fig. 4a) reveals that a series of $\mathrm{Ti}-\mathrm{Al}$ intermetallic compounds were formed in this bio-inspired hybrid composite. The composition distributions of $\mathrm{Ti}$ and Al show that the $\mathrm{Ti}$ contents decrease from the outer layer to the inner layer, while the Al contents show an opposite trend (Fig. 4b). Quantified results of these layers by EDS analysis are listed in Table 1 . Combining the results of $\mathrm{XRD}$ and EDS, the phases were identified as $\mathrm{Ti}, \mathrm{Ti}_{3} \mathrm{Al}$, TiAl, $\mathrm{TiAl}_{2}$ and $\mathrm{TiAl}_{3}$, respectively, from the outer layer (Ti) to the inner layer ( $\mathrm{Ti}-\mathrm{Al}$ intermetallics).

Previous studies [32, 33] have pointed out that the reaction of $\mathrm{Ti}$ and $\mathrm{Al}$ begin at $600{ }^{\circ} \mathrm{C}$; therefore, it is likely that $\mathrm{TiAl}_{3}$ phase nucleates first at the interface when the $\mathrm{Ti}$ and $\mathrm{Al}$ plates are heated to high temperature, e.g., $625^{\circ} \mathrm{C}$ in this work [34, 35]. Then, the nucleated $\mathrm{TiAl}_{3}$ particles gradually grow and connect into a continuous thin layer between the $\mathrm{Ti}$ and $\mathrm{Al}$ layers. The nucleation dynamics of $\mathrm{TiAl}_{3}$ formation greatly depends on the solute concentration gradient at certain temperatures, which drives the elements (mainly $\mathrm{Al}$ ) to diffuse between the different layers [36]. In our experiments, the diffusion-controlled reaction was most likely dominated during the first two holding temperature $\left(625\right.$ and $\left.650{ }^{\circ} \mathrm{C}\right)$ stages. When the plates were heated to a temperature higher than the melting point of $\mathrm{Al}\left(660{ }^{\circ} \mathrm{C}\right)$, the $\mathrm{Al}$ layers were completely melted, contacting directly with the Ti foils. A prior study [36] has revealed that the self-propagating combustion reaction can take place when the melt $\mathrm{Al}$ contacts with $\mathrm{Ti}$, forming $\mathrm{TiAl}_{3}$ phase. In our experiments, the temperature range was between 600 and $900{ }^{\circ} \mathrm{C}$; therefore, the two reaction modes, the diffusion-controlled reaction and the selfpropagating combustion reaction, may coexist. Note that these two reaction modes result in only one type of primary phase, i.e., $\mathrm{TiAl}_{3}$.

The atomic ratio of $\mathrm{Ti} / \mathrm{Al}$ is about 4.7 in the pristine foils stacking. Therefore, the Al layer was completely consumed through the reaction with $\mathrm{Ti}$, and the initial $\mathrm{Ti} / \mathrm{Al}$ interfaces were replaced by $\mathrm{Ti} / \mathrm{TiAl}_{3}$ layers. However, studies have 

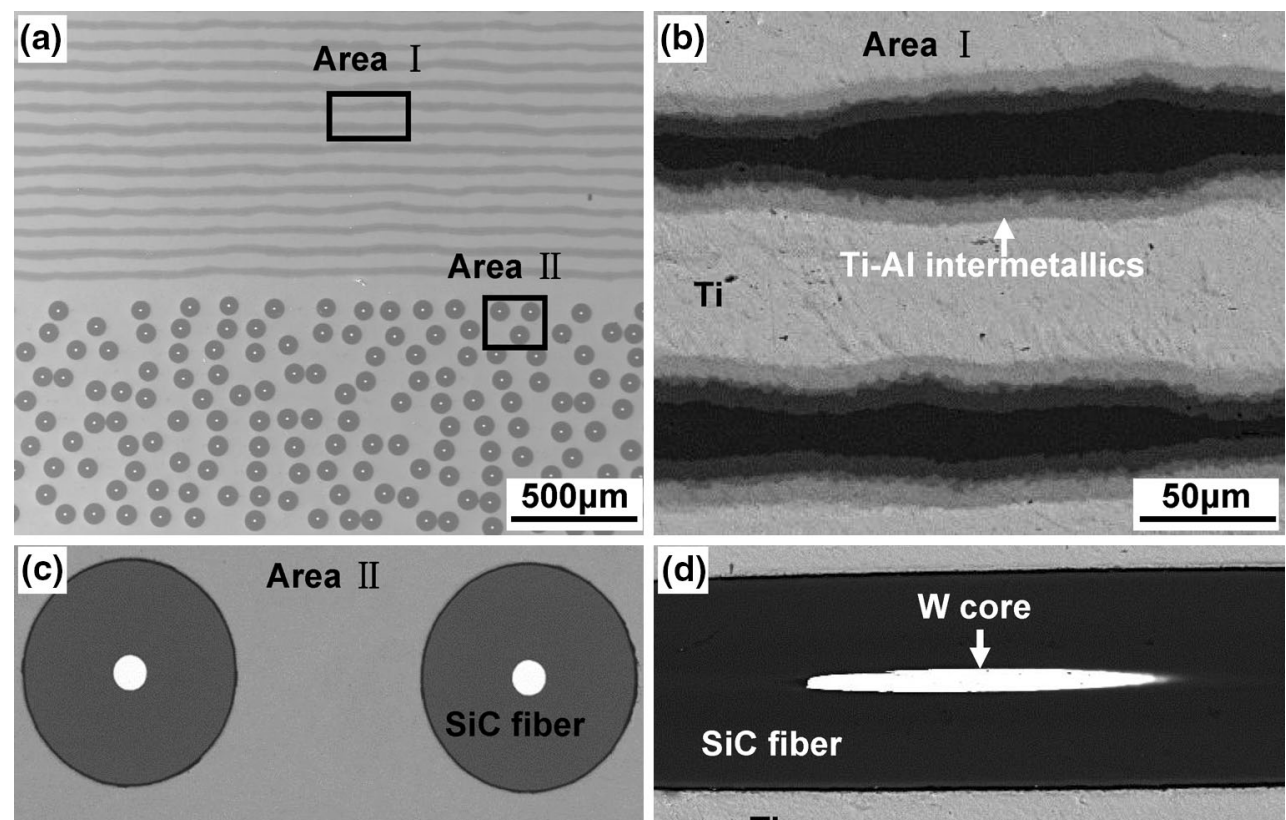

Ti

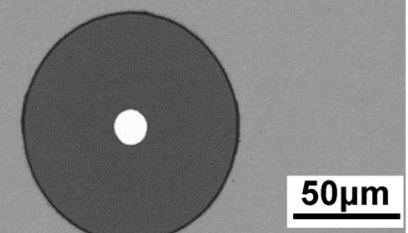

Ti

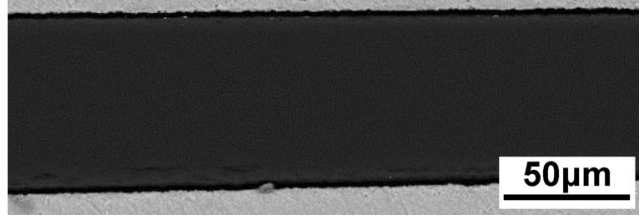

Fig. 3 Microstructure of the bio-inspired hybrid composite: a cross section; b local magnified regions showing the Ti-Al intermetallic multilayered part; $\mathrm{SiC}$ fibers-reinforced $\mathrm{Ti}$ matrix part in the $\mathbf{c}$ cross and $\mathbf{d}$ longitudinal sections

shown that the $\mathrm{Ti} / \mathrm{TiAl}_{3}$ interface is unstable at high temperature [35], and the $\mathrm{Al}$ atoms in the $\mathrm{TiAl}_{3}$ layer tend to diffuse into the $\mathrm{Ti}$ layer due to the solute concentration gradient. Meanwhile, Ti atoms in the Ti layer also tend to diffuse into the $\mathrm{TiAl}_{3}$ layer. Consequently, TiAl and $\mathrm{Ti}_{3} \mathrm{Al}$ phase would form at the interface [37, 38], which further leads to the formation of $\mathrm{TiAl}_{2}$ phase at the interface, as the formation of $\mathrm{TiAl}_{2}$ usually takes the $\mathrm{TiAl}$ as the intermediate phase [33]. It is noted that the formation of $\mathrm{Ti}_{3} \mathrm{Al}$, $\mathrm{TiAl}$ and $\mathrm{TiAl}_{2}$ may occur almost simultaneously through the following reaction: $\mathrm{TiAl}_{3}+\mathrm{Ti} \rightarrow \mathrm{Ti}_{3}$ $\mathrm{Al}+\mathrm{TiAl}+\mathrm{TiAl}_{2}$ [39]. Immediately after the nucleation of different $\mathrm{Ti}-\mathrm{Al}$ intermetallics phases, these $\mathrm{Ti}-\mathrm{Al}$ phases start to grow due to the diffusion-controlled kinetics and finally form irregular interface as a result of restricting competition growth mechanism [40]. It is pointed out that the interfaces between different phases tend to stabilize through a smaller concentration gradient along the interface, minimizing the surface free energy. Thus, the final interface sequence is $\mathrm{Ti} / \mathrm{Ti}_{3} \mathrm{Al} / \mathrm{TiAl} / \mathrm{TiAl}_{2} / \mathrm{TiAl}_{3}$ [39]. It should be mentioned that the thickness of each kind of TiAl intermetallic compound layer varied from one to another. This is mainly because the diffusion coefficient of $\mathrm{Ti}$ and $\mathrm{Al}$ elements are diverse in different reaction layers, resulting in various reaction rates between these phases [41].

In the continuous $\mathrm{SiC}$ fibers-reinforced $\mathrm{Ti}$ matrix composite part, the interface reaction is much weaker than the previous reports $[25,42]$. Detailed examination shows that a quite thinner reaction layer is formed in Fig. 4c as compared with that in Refs. [25, 42]. The elements distribution crossing the $\mathrm{SiC}$ fiber and $\mathrm{Ti}$ matrix interface was analyzed, and the result is shown in Fig. 4d. A thin Si- and C-enriched layer (about $1 \mu \mathrm{m}$ thick) is formed on the $\mathrm{Ti}$ matrix side. However, no $\mathrm{Ti}-\mathrm{C}$ and $\mathrm{Ti}-\mathrm{Si}$ compounds, as mentioned in previous reports [26, 43], are detected by $\mathrm{XRD}$, probably due to their very low contents. The coating carbon layer on the $\mathrm{SiC}$ fibers is proved to reduce the degree of reaction [44]. Moreover, modified parameters, including lower reaction temperature, shorter reaction time and lower pressure than previous work, were adopted in this work [25, 42, 45], which are beneficial to weaken the interface reaction [26] and lead to less brittle compounds [44].

\subsection{Flexural Property}

Figure 5 plots the typical stress-strain curve of the threepoint bending test. The stress increases elastically at the 

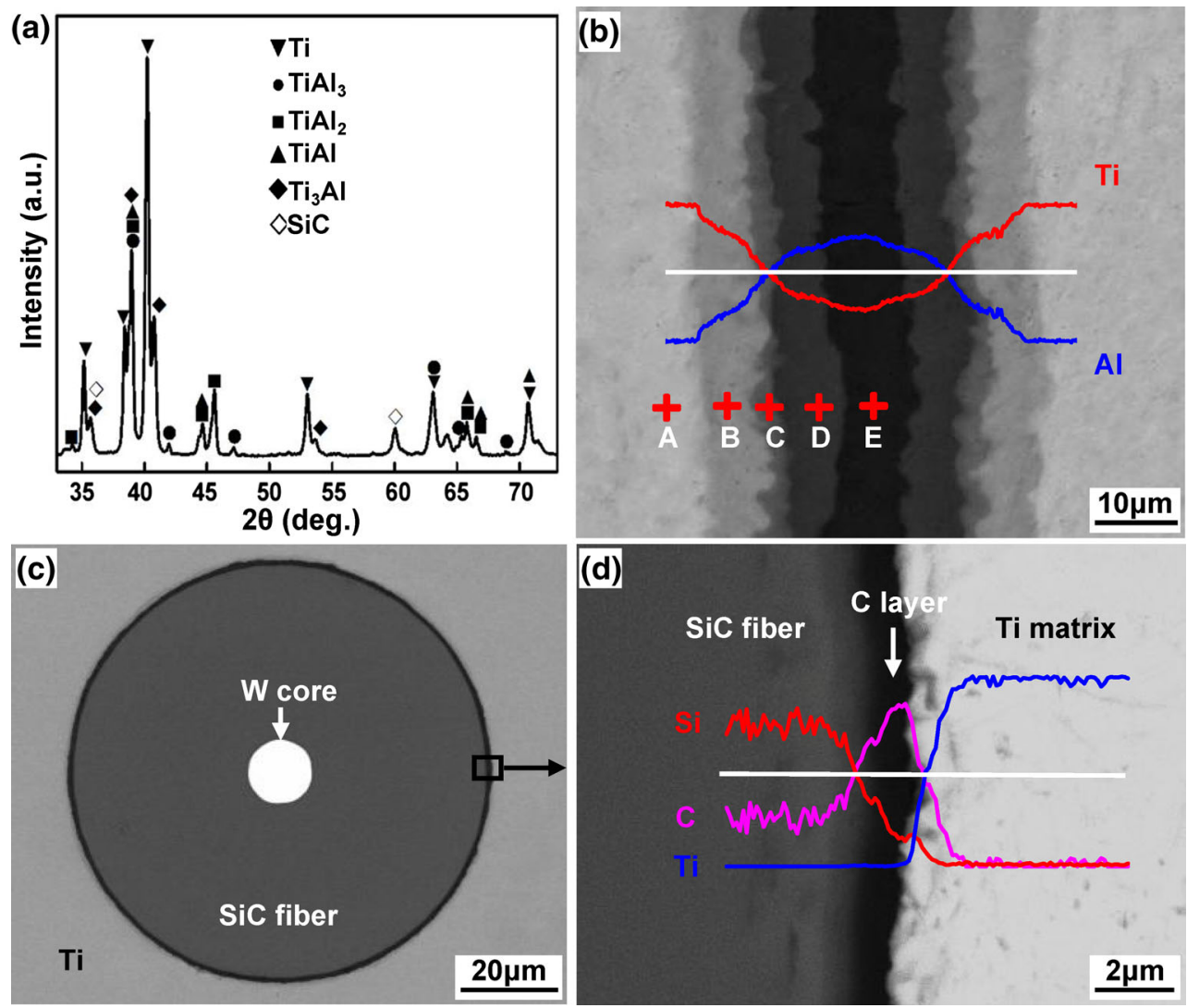

Fig. 4 Interface reaction in the bio-inspired hybrid composite: a XRD result; $\mathbf{b}$ SEM image and element distributions crossing the phases of the $\mathrm{Ti}-\mathrm{Al}$ intermetallic multilayers; c SEM image showing the morphology of a SiC fiber and Ti matrix; $\mathbf{d}$ elements distribution in the SiC fiber and Ti matrix

Table 1 EDS points analysis corresponding to Fig. $4 \mathrm{~b}$

\begin{tabular}{llllll}
\hline & Spot A $(\%)$ & Spot B $(\%)$ & Spot C $(\%)$ & Spot D $(\%)$ & Spot E (\%) \\
\hline Al & 1.66 & 25.19 & 46.73 & 67.05 & 74.43 \\
$\mathrm{Ti}$ & 98.34 & 74.81 & 53.27 & 32.95 & 25.57 \\
Phase & $\mathrm{Ti}$ & $\mathrm{Ti}_{3} \mathrm{Al}$ & $\mathrm{TiAl}$ & $\mathrm{TiAl}_{2}$ & $\mathrm{TiAl}_{3}$ \\
\hline
\end{tabular}

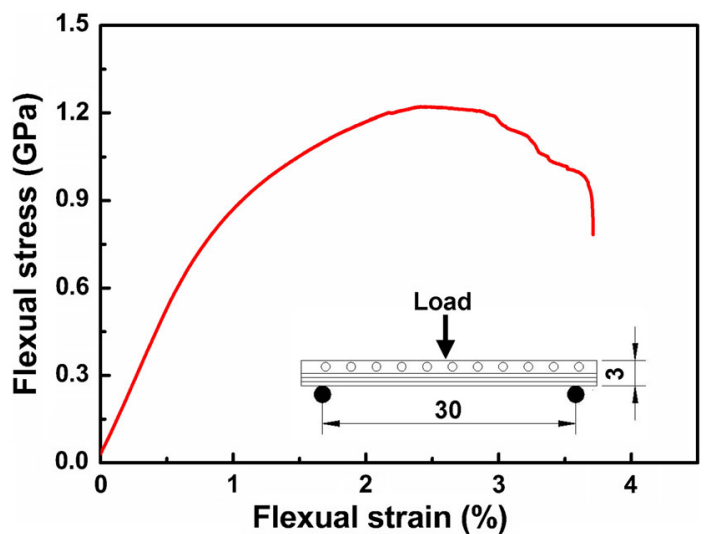

Fig. 5 Typical stress-strain curve of the bio-inspired hybrid composite in the three-point bending test beginning upon loading and then further increases at a reduced rate to the maximum stress. Accordingly, the flexural strength of the bio-inspired hybrid composite was measured to be $1.21 \pm 0.16 \mathrm{GPa}$ at the strain of $\sim 2.5 \%$. It is interesting to note that the step-like responses occurred after the maximum stress upon further loading. After a certain strain, e.g., $3.7 \%$, the specimen was fractured completely.

The measured flexural strength in this work is much higher than previous results with similar structure [25], increased by $\sim 33 \%$, from $\sim 0.9$ to $\sim 1.2 \mathrm{GPa}$. This is supposed to be resulted from the optimized parameters used in this study for the hot-pressing sintering processing, i.e., the lower temperature and shorter time, which decrease the content of the brittle compounds at the interface, as compared to previous studies [25], enhancing the interfacial debonding strength between $\mathrm{SiC}$ fibers and $\mathrm{Ti}$ matrix. 
The delayed loading is also conducive to ensure the temperature of the internal specimen uniform when load applied, which guarantees Ti foils having good deformation ability to fill the gaps between the SiC fibers. Under this circumstance, the damage to $\mathrm{SiC}$ fibers under press load, where cracks could initiate [46], is likely to be reduced. The integrity of $\mathrm{SiC}$ fibers can be maintained in general, and the enhancement effect of SiC fibers [46] in this hybrid composite is fully achieved. Moreover, the flexural strength in this work is close to that of the continuous $\mathrm{SiC}$ fibers-reinforced $\mathrm{Ti}$ matrix composite $(1224 \pm 30 \mathrm{MPa})$ fabricated by similar process, which contributed to the much higher strength of the $\mathrm{SiC}$ fibersreinforced $\mathrm{Ti}$ matrix composite than that of the Ti intermetallic multilayered composite [25]. In addition, the flexural strength is also higher than that of the other similar bio-inspired materials $(803 \pm 50 \mathrm{MPa})$ [42] that were fabricated with a similar processing routine, but with different processing parameters.

The lateral surfaces in the intermediate process of bending test after maximum load and the complete fractured surfaces of the tested samples were examined in SEM, and a few typical images are presented in Figs. 6 and 7. It is observed that the propagation route of the cracks presents an " $S$ " shape, along with complex twists and turns, as shown in Fig. 6a, similar to the fracture morphology of the native rib specimen [10]. This indicates that a great amount of energy was absorbed by possible cracks branching, blunting, deflection and bridging during the deformation process [47]. Accordingly, the bending fractured surface is not smooth, with jagged fluctuations between the layers and in the lamellar structure (Fig. 7a).

Discrete microcracks are visible in each Ti-Al intermetallics layer, as indicated by arrows in Fig. 6b. It seems that most of the cracks were either crossed completely through the Ti-Al intermetallics layer or radiated from the interface of the intermetallics layer and Ti matrix layer and then, stopped inside the $\mathrm{Ti}-\mathrm{Al}$ intermetallics layer. These results probably suggest that the nucleation of the microcracks mostly occurs at the interface between the $\mathrm{Ti}-\mathrm{Al}$ intermetallics layer and $\mathrm{Ti}$ layer and then propagates along the $\mathrm{Ti}-\mathrm{Al}$ intermetallics layer, consistent with the results in previous reports $[16,47]$. Cracks deflection and

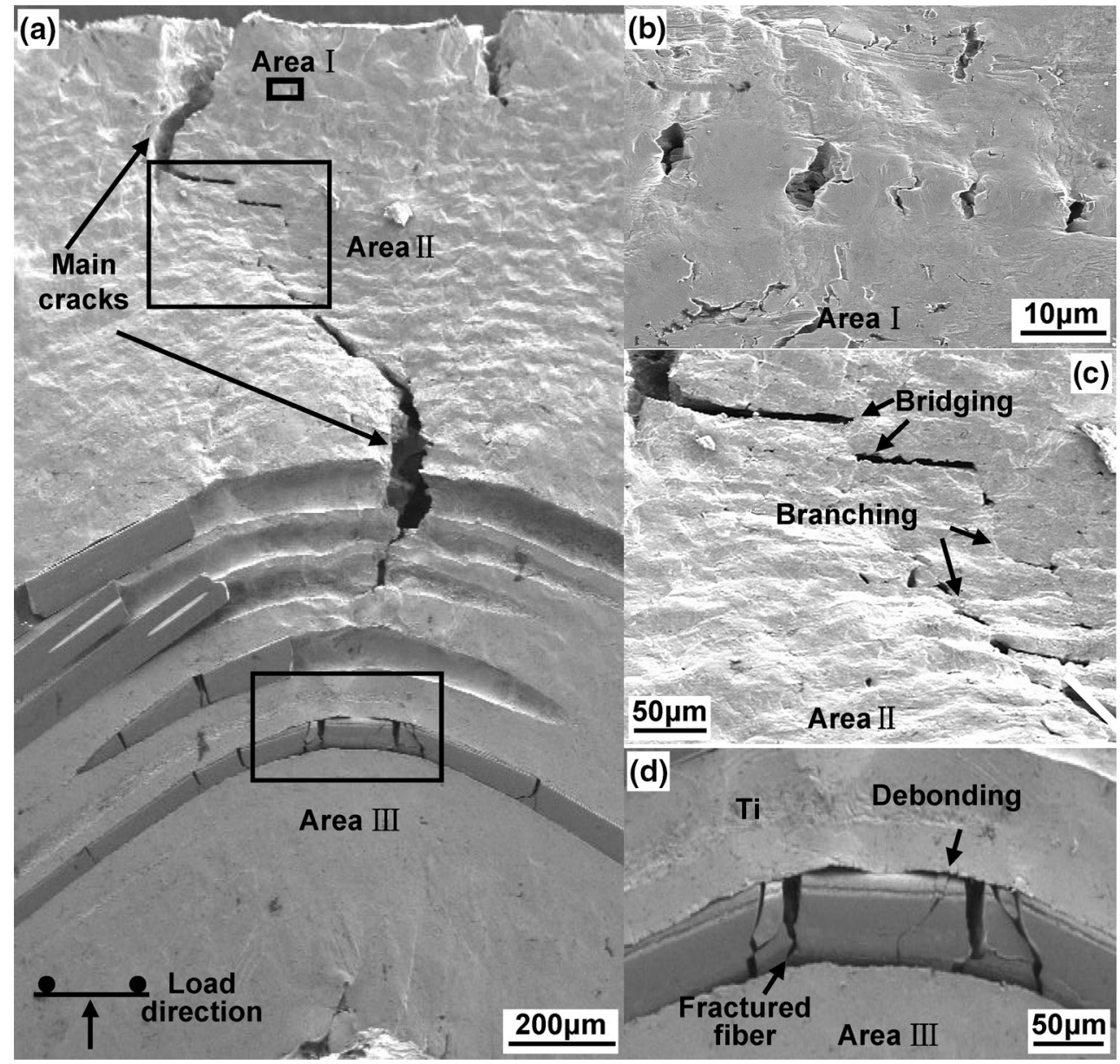

Fig. 6 Morphology and the main cracks propagation of the bio-inspired hybrid composite: a overall SEM image; magnified SEM images of $\mathbf{b}$ area I, $\mathbf{c}$ area II, $\mathbf{d}$ area III in $\mathbf{a}$, respectively 


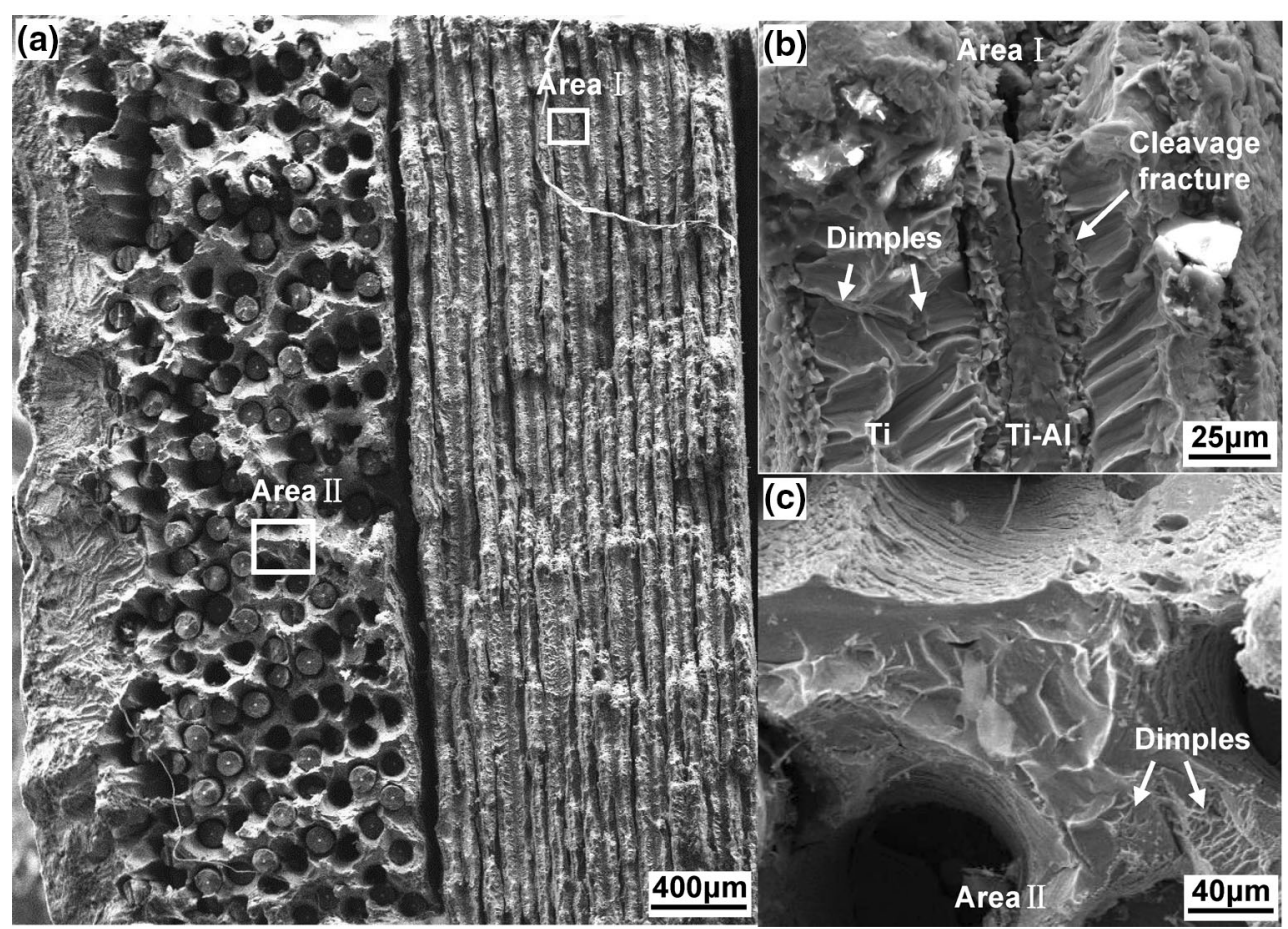

Fig. 7 Fractured surfaces of the bio-inspired hybrid composite after three-point bending test: a SEM image showing the overall morphology of the fractured surface; magnified images showing the fracture morphologies of $\mathbf{b} \mathrm{Ti}-\mathrm{Al}$ intermetallic multilayered composite, $\mathbf{c} \mathrm{SiC}$ fibersreinforced Ti matrix composite, respectively

branching characteristics are also visible at the interface of $\mathrm{Ti}$ layer and $\mathrm{Ti}-\mathrm{Al}$ intermetallics layer due to constraint effect caused by the ductile nature of the Ti layer, as shown in Fig. 6c. Upon increasing stress, plastic deformation started to take place within the ductile Ti layer. It is pointed out here that severe plastic deformation within the ductile Ti layer may also cause the nucleation of microcracks, and the shear bands would be formed at the Ti layers, leading to fracture [48]. When the ductile Ti layer broke after yielding, cracks propagated quickly into the neighboring $\mathrm{Ti}-\mathrm{Al}$ intermetallics layer. Therefore, the cracks are connected in different layers.

The crack propagations along the interfaces in this hierarchical structure are likely to be responsible for decreasing stress and lower platform segments formed in the stress-strain curve after the stress reached the maximum value. However, the dominant mechanism can only be revealed by in situ observations, for example, in situ SEM observation [25, 42] or synchrotron X-ray tomographic quantification [49], which were not done in this study. The fractured surface of the sample (Fig. 7b) confirms the main deformation and fracture mechanism as stated above [50], that is, the fracture of $\mathrm{Ti}$ layer by micropore aggregation mechanism [47], as indicated by the presence of large dimples, and the cleavage fracture mechanism [16] for the Ti-Al intermetallics layer, as indicated by arrows in Fig. $7 \mathrm{~b}$.

The deformation process in the $\mathrm{SiC}$ fibers-reinforced composite part can be elucidated as follows. Due to the increasing stress during the loading process, cracks propagated gradually to the $\mathrm{SiC}$ fibers-reinforced $\mathrm{Ti}$ matrix composite part. Under the bending forces, $\mathrm{SiC}$ fibers were debonded from the Ti matrix and fractured firstly due to their brittle nature [25]. However, the cracks were stopped at the interface of $\mathrm{SiC}$ fibers and $\mathrm{Ti}$ matrix, as shown in Fig. 6d. Plastic deformation occurred in the Ti matrix under applied force, as indicated by the presence of large dimples [47] in Fig. 7c. The Ti matrix part was still able to support the structure and to bear the loads, until the final complete failure. Overall, benefited from the hierarchical structure that combines the hard layer and ductile layer, the bio-inspired hybrid composite can inhibit the cracks expansion effectively and might be a potential protective material for vehicle motors and aerospace structures.

\section{Conclusions}

Inspired by the structure of the turtle carapace, a bio-inspired hybrid composite, combining the $\mathrm{Ti}-\mathrm{Al}$ intermetallic multilayered composite and continuous $\mathrm{SiC}$ fibers-reinforced Ti matrix composite, was successfully fabricated. The microstructure and flexural properties of this bio-inspired hybrid composite were investigated. The conclusions could be drawn as follows: 
1. In the $\mathrm{Ti}-\mathrm{Al}$ intermetallic multilayered composite part, several sub-layers of $\mathrm{Ti}-\mathrm{Al}$ intermetallics were formed, including $\mathrm{Ti}_{3} \mathrm{Al}, \mathrm{TiAl}, \mathrm{TiAl}_{2}$ and $\mathrm{TiAl}_{3}$ phases. In the continuous $\mathrm{SiC}$ fibers-reinforced $\mathrm{Ti}$ matrix part, the SiC fibers and the Ti matrix were well bonded with a thin reaction layer.

2. The three-point bending test shows that the flexural strength of the bio-inspired hybrid composite is $1.21 \pm 0.16 \mathrm{GPa}$. Cracks deflection, bridging and blunting occurred at the interfaces between the brittle $\mathrm{Ti}-\mathrm{Al}$ intermetallics layers/SiC fibers and ductile $\mathrm{Ti}$ components. The hierarchical structure combining the ductile $\mathrm{Ti}$ with brittle reinforcements can effectively enhance the deformation behavior by limiting cracks extension while maintaining deformation capability.

Acknowledgements This work was financially supported by the Defense Industrial Technology Development Program (JCKY2017205B032) and National Natural Science Foundation of China (Nos. 51405458, 51371066 and 51331005).

\section{References}

[1] W. Yang, I.H. Chen, B. Gludovatz, E.A. Zimmermann, R.O. Ritchie, M.A. Meyers, Adv. Mater. 25, 31-48 (2013)

[2] I.H. Chen, W. Yang, M.A. Meyers, Acta Biomater. 28, 2-12 (2015)

[3] S. Krauss, E. Monsonego-Ornan, E. Zelzer, P. Fratzl, R. Shahar, Adv. Mater. 21, 407-412 (2009)

[4] H. Rhee, M.F. Horstemeyer, Y. Hwang, H. Lim, H.E. Kadiri, W. Trim, Mater. Sci. Eng. C Mater. 29, 2333-2339 (2009)

[5] K. Balani, R.R. Patel, A.K. Keshri, D. Lahiri, A. Agarwal, J. Mech. Behav. Biomed. Mater. 4, 1440-1451 (2011)

[6] B. Achrai, H.D. Wagner, Acta Biomater. 9, 5890-5902 (2013)

[7] R. Damiens, H. Rhee, Y. Hwang, S.J. Park, Y. Hammi, H. Lim, M.F. Horstemeyer, J. Mech. Behav. Biomed. Mater. 6, 106-112 (2012)

[8] B. Achrai, B. Bar-On, H.D. Wagner, J. Mech. Behav. Biomed. Mater. 30, 223-233 (2014)

[9] B. Achrai, H.D. Wagner, Mater. Sci. Eng. C Mater. 53, 128-133 (2015)

[10] B. Achrai, B. Baron, H.D. Wagner, Bioinspir Biomim. 10, 016009 (2015)

[11] C. Qiang, N.M. Pugno, J. Mech. Behav. Biomed. Mater. 19, 3-33 (2013)

[12] D.V. Lazurenko, I.A. Bataev, V.I. Mali, A.A. Bataev, I.N. Maliutina, V.S. Lozhkin, M.A. Esikov, A.M.J. Jorge, Mater. Des. 102, 122-130 (2016)

[13] G. Min, J.M. Lee, S.B. Kang, H.W. Kim, Mater. Lett. 60, 3255-3259 (2006)

[14] P. Zhou, C. Guo, E. Wang, Z. Wang, Y. Chen, F. Jiang, Mater. Sci. Eng. A Struct. 665, 66-75 (2016)

[15] T. Li, F. Grignon, D.J. Benson, K.S. Vecchio, E.A. Olevsky, F. Jiang, A. Rohatgi, R.B. Schwarz, M.A. Meyers, Mater. Sci. Eng. A Struct. 374, 10-26 (2004)

[16] B. Liu, L. Huang, X. Rong, L. Geng, F. Yin, Compos. Sci. Technol. 126, 94-105 (2016)
[17] M. Fan, J. Domblesky, K. Jin, L. Qin, S. Cui, X. Guo, N. Kim, J. Tao, Mater. Des. 99, 535-542 (2016)

[18] A. Hagenau, M.H. Suhre, T.R. Scheibel, Prog. Polym. Sci. 39, 1564-1583 (2014)

[19] M. Bhattacharjee, S. Miot, A. Gorecka, K. Singha, M. Loparic, S. Dickinson, A. Das, N.S. Bhavesh, A.R. Ray, I. Martin, Acta Biomater. 8, 3313-3325 (2012)

[20] B. Chen, D. Yin, W. Ye, S. Lin, J. Fan, J. Gou, Mater. Des. 86, 686-691 (2015)

[21] H. Humburg, D. Zhu, S. Beznia, F. Barthelat, Compos. Sci. Technol. 72, 1012-1019 (2012)

[22] D. Li, G. Chen, L. Jiang, G. Wu, Acta Metall. Sin. (Engl. Lett.) 28, 1175-1182 (2015)

[23] H. Kurita, E. Feuillet, T. Guillemet, J.M. Heintz, A. Kawasaki, J.F. Silvain, Acta Metall. Sin. (Engl. Lett.) 27, 714-722 (2014)

[24] Q. Cheng, M. Li, L. Jiang, Z. Tang, Adv. Mater. 24, 1838-1843 (2012)

[25] K. Zhu, W. Yu, Y. Aman, T. Jing, J. Mater. Sci. 51, 8747-8760 (2016)

[26] C. Zhou, K. Yang, Y. Lu, Acta Metall. Sin. (Engl. Lett.) 11, 307-312 (1998)

[27] B.S. Majumdar, T.E. Matikas, D.B. Miracle, Compos. Part B Eng. 29, 131-145 (1998)

[28] J. Ye, Y. Qiu, Y. He, J. Ma, X. Zhang, C. Huang, Sci. Eng. Compos. Mater. (2015)

[29] U. Santhosh, J. Ahmad, G. Ojard, R. Miller, Y. Gowayed, Compos. Part B Eng. 90, 97-106 (2016)

[30] Y. Sun, S.K. Vajpai, K. Ameyama, C. Ma, J. Alloys Compd. $\mathbf{5 8 5}, 734-740(2014)$

[31] H. Li, M. Li, W. Yu, H. Liu, Rare Met. 35, 235-241 (2016)

[32] M.C. Kim, M.H. Oh, J.H. Lee, H. Inui, M. Yamaguchi, D.M. Wee, Mater. Sci. Eng. A Struct. 239, 570-576 (1997)

[33] F.J.J. van Loo, G.D. Rieck, Acta Metall. 21, 61-71 (1973)

[34] S. Wohlert, R. Bormann, J. Appl. Phys. 85, 825-832 (1999)

[35] J. Zhang, Intermetallics 18, 2292-2300 (2010)

[36] J. Mackowiak, L.L. Shreir, J. Less Common Met. 15, 341-346 (1968)

[37] J. Luo, V.L. Acoff, Mater. Sci. Eng. A Struct. 433, 334-342 (2006)

[38] G. Feng, Z. Li, R. Liu, S. Feng, Acta Metall Sin (Engl. Lett.) 28, 405-413 (2015)

[39] L. Xu, Y. Cui, Y. Hao, R. Yang, Mater. Sci. Eng. A Struct. 435, 638-647 (2006)

[40] J. Oh, W.C. Lee, S.G. Pyo, W. Park, S. Lee, N.J. Kim, Metall. Mater. Trans. A 33, 3649-3659 (2002)

[41] Y. Mishin, C. Herzig, Acta Mater. 48, 589-623 (2000)

[42] W. Yu, K. Zhu, Y. Aman, Z. Guo, S. Xiong, Mater. Des. 101, 102-108 (2016)

[43] L. Yu, Y. Lu, D. Li, H. Ye, Acta Metall. Sin. 32, 318-322 (1996)

[44] Y. Fu, N. Shi, D. Zhang, R. Yang, Mater. Sci. Eng. A Struct. 426, 278-282 (2006)

[45] H. Qu, X. Ren, H. Hou, B. Zhao, Mater. Sci. Technol. 30, 1770-1773 (2014)

[46] G. Feng, Y. Yang, X. Luo, J. Li, B. Huang, Y. Chen, Compos. Part B Eng. 68, 336-342 (2015)

[47] Y. Sun, J. Chen, F. Ma, K. Ameyama, W. Xiao, C. Ma, Mater. Charact. 102, 165-172 (2015)

[48] T. Li, F. Jiang, E.A. Olevsky, K.S. Vecchio, M.A. Meyers, Mater. Sci. Eng. A Struct. 443, 1-15 (2007)

[49] S. Shuai, E. Guo, A.B. Phillion, M.D. Callaghan, T. Jing, P.D. Lee, Acta Mater. 118, 260-269 (2016)

[50] Y. Liu, J. Zhang, S.J. Li, W. Hou, H. Wang, Q. Xu, Y. Hao, R. Yang, Acta Metall. Sin. (Engl. Lett.) 30(12), 1163-1168 (2017) 